BMC

Genetics

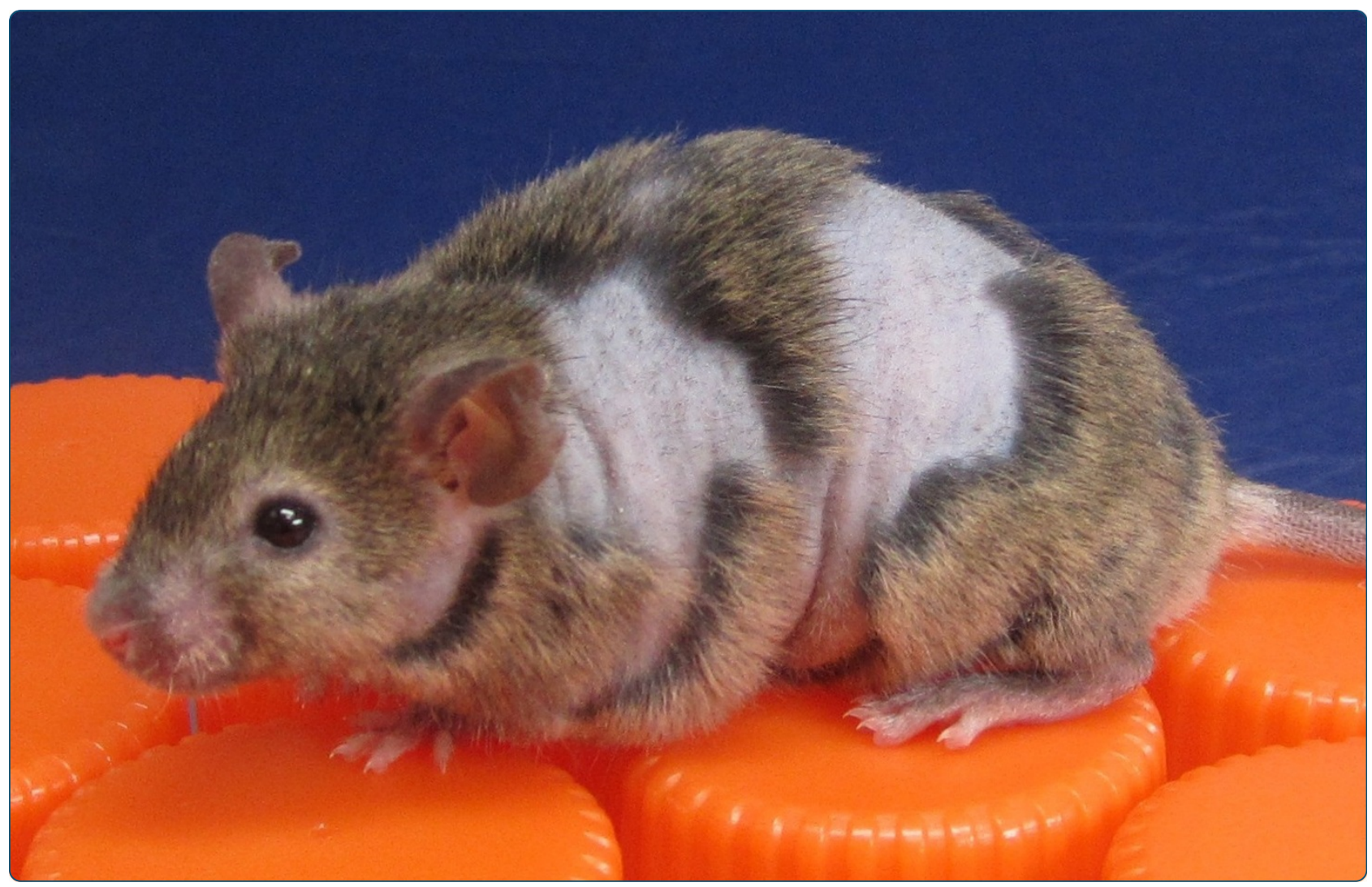

The juvenile alopecia mutation (jal) maps to mouse Chromosome 2, and is an allele of GATA binding protein 3 (Gata3)

Ramirez et al.

() Biomed Central 


\title{
The juvenile alopecia mutation (jal) maps to mouse Chromosome 2, and is an allele of GATA binding protein 3 (Gata3)
}

Francisco Ramirez ${ }^{\dagger}$, Aaron M Feliciano ${ }^{\dagger}$, Elisabeth B Adkins, Kevin M Child, Legairre A Radden II, Alexis Salas, Nelson Vila-Santana, José M Horák, Samantha R Hughes, Damek V Spacek and Thomas R King*

\begin{abstract}
Background: Mice homozygous for the juvenile alopecia mutation (jal) display patches of hair loss that appear as soon as hair develops in the neonatal period and persist throughout life. Although a report initially describing this mouse variant suggested that jal maps to mouse Chromosome 13, our preliminary mapping analysis did not support that claim.

Results: To map jal to a particular mouse chromosome, we produced a 103-member intraspecific backcross panel that segregated for jal, and typed it for 93 PCR-scorable, microsatellite markers that are located throughout the mouse genome. Only markers from the centromeric tip of Chromosome 2 failed to segregate independently from jal, suggesting that jal resides in that region. To more precisely define jal's location, we characterized a second, 374-member backcross panel for the inheritance of five microsatellite markers from proximal Chromosome 2. This analysis restricted jal's position between D2Mit359 and D2Mit80, an interval that includes II2ra (for interleukin 2 receptor, alpha chain), a gene that is known to be associated with alopecia areata in humans. Complementation testing with an engineered null allele of $1 / 2 \mathrm{ra}$, however, showed that jal is a mutation in a distinct gene. To further refine the location of jal, the 374-member panel was typed for a set of four single-nucleotide markers located between D2Mit359 and D2Mit80, identifying a $0.55 \mathrm{Mb}$ interval where jal must lie. This span includes ten genesonly one of which, Gata3 (for GATA binding protein 3) -is known to be expressed in skin. Complementation testing between jal and a Gata3 null allele produced doubly heterozygous, phenotypically mutant offspring.

Conclusions: The results presented indicate that the jal mutation is a mutant allele of the Gata3 gene on mouse Chromosome 2. We therefore recommend that the jal designation be changed to Gata ${ }^{j a l}$, and suggest that this mouse variant may provide an animal model for at least some forms of focal alopecia that have their primary defect in the hair follicle and lack an inflammatory component.
\end{abstract}

Keywords: Mouse model, Focal alopecia, Positional candidate approach, II2ra, Gata3, Complementation testing

\section{Background}

The initial assignment of spontaneous hair variants to particular genes can be a crucial first step in the longterm investigation into the role these genes play in the normal (and disrupted) development of the mammalian integument (for example, see refs. [1-9]). Unfortunately, several naturally-occurring hair and skin variants in mice

\footnotetext{
*Correspondence: kingt@ccsu.edu

${ }^{\dagger}$ Equal contributors

Biomolecular Sciences, Central Connecticut State University, 1615 Stanley Street, New Britain, CT 06053, USA
}

remain out-of-the-mainstream of modern biological investigation, simply because they have not yet been assigned to a causative gene or even, in some cases, to a particular chromosome. One such variant is generated by the recessive juvenile alopecia mutation, abbreviated jal. This variant arose on the standard $\mathrm{C} 3 \mathrm{H} / \mathrm{HeJ}$ genetic background, and its origin and novel phenotype were described in a single brief paper published by McElwee et al. in 1999 [10]. Homozygous mice exhibit patchy hair loss (see Figure 1), wavy truncal hair, defects in hair follicles, and abnormalities in hair growth cycle regulation. 


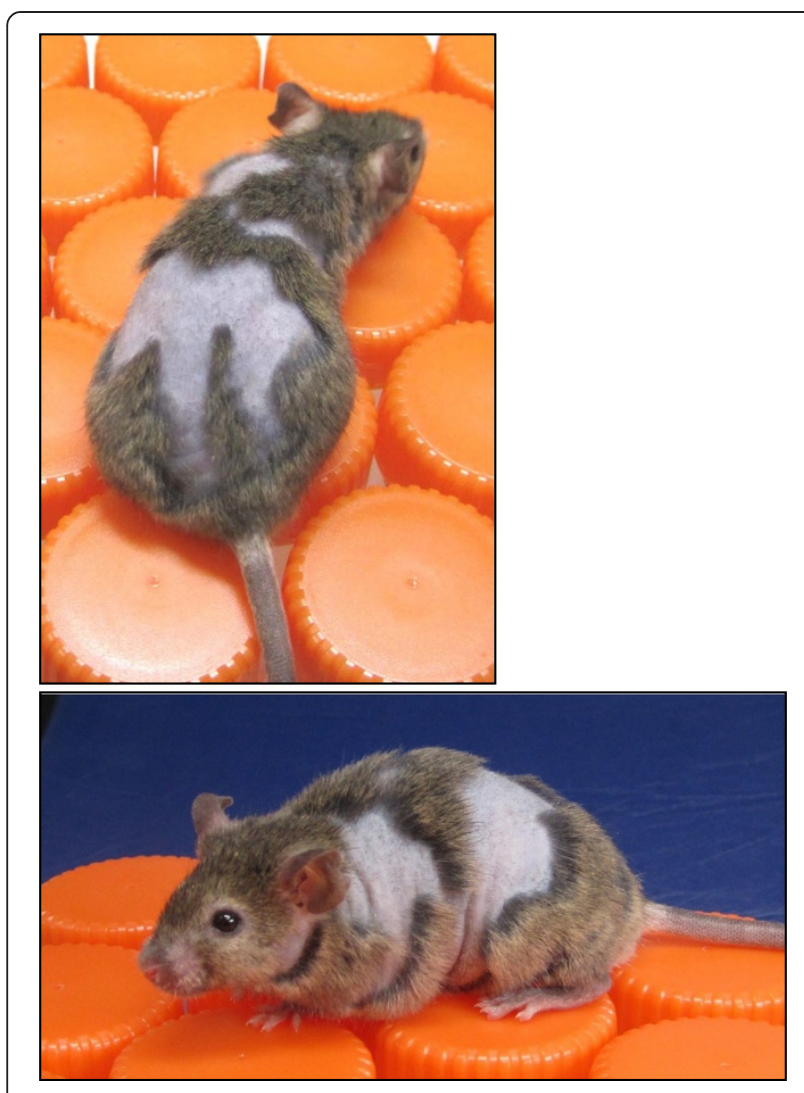

Figure $1 \mathrm{~A}$ three-month-old $\mathrm{C} 3 \mathrm{H} / \mathrm{HeJ}-$ jal/J mouse, homozygous for jal.

Vibrissae defects are apparent at birth, and focal alopecia is evident as soon as hair develops in the neonatal period. Although McElwee and coworkers suggested that jal is located on mouse Chromosome (Chr) 13 [10], our preliminary backcross analysis [11] clearly showed that jal does not map anywhere on that chromosome.

Here, we describe the completed molecular-genetic analysis of a pair of large backcross families that allowed us to locate jal on mouse Chr 2, and then restrict its location to a small, defined interval at the centromeric tip. In addition, we describe complementation testing between jal and engineered null alleles of two co-localizing candidate genes, one of which (Gata3, for GATA binding protein 3 ) we identify as the likely basis of the juvenile alopecia phenotype in mice.

\section{Methods}

Mice

Mice from the standard inbred strains C57BL/6 J, C3H/ $\mathrm{HeJ}, \mathrm{A} / \mathrm{J}$, as well as inbred $\mathrm{C} 3 \mathrm{H} / \mathrm{HeJ}-\mathrm{jal} / \mathrm{J}$ mice were obtained from The Jackson Laboratory (Bar Harbor, ME, USA). Mice homozygous for the mutant jal allele were most reliably identified by vibrissae defects that are first evident shortly after birth. By two weeks of age, homozygotes present with distinct patches of hair loss (most often on the dorsal surface) that persist throughout life (see Figure 1). The amount of body surface affected varies widely among homozygous individuals (from less than 5\% to greater than 95\% [see Additional file 1]), even within the inbred $\mathrm{C} 3 \mathrm{H} / \mathrm{HeJ}-\mathrm{jal}$ strain. While both male and female jal/jal homozygotes are fertile, we have maintained the $\mathrm{C} 3 \mathrm{H} / \mathrm{HeJ}-\mathrm{jal}$ line since 2009 by crossing heterozygous females with homozygous males, to produce segregating litters.

Mice carrying a targeted mutation in the interleukin 2 receptor, alpha chain gene $\left(I l 2 r a^{t m 1 D w}\right)$ were also obtained from The Jackson Laboratory. The creation of the $I l 2 r a^{t m 1 D w}$ loss-of-function allele is described by Willerford et al. [12]. In brief, these investigators used homologous recombination to replace a $5.5 \mathrm{~kb}$ segment of the Il2ra gene which contains Exons 2 and 3 and encodes the interleukin 2 binding site [13] with a phosphoglycerate kinase (PGK)-neomycin resistance (neo) cassette. Mice carrying a targeted mutation in the GATA binding protein 3 gene $\left(\right.$ Gata $^{\text {tm1Gsv }}{ }^{\text {) }}$ were kindly donated by Dr. James Douglas Engel (University of Michigan, Ann Arbor, MI, USA). The creation of the Gata3 ${ }^{\text {tm1Gsv }}$ loss-of-function/reporter allele is described by van Doorninck et al. [14]. In brief, these investigators replaced $157 \mathrm{bp}$ in Exon 2, including the start codon, with a nuclear localization signal (nls)-lac $Z$ fusion cassette, followed by a PGK-hygromycin resistance (hyg) cassette.

All studies were in compliance with protocols approved by the Institutional Care and Use Committee (IACUC) at Central Connecticut State University (New Britain, CT, USA).

\section{DNA isolation and analysis}

Genomic DNA was isolated from $3 \mathrm{~mm}$ tail tip biopsies taken from two-week-old mice, using Nucleospin kits from BD Biosciences (Palo Alto, CA, USA). The polymerase chain reaction (PCR) was performed using the Titanium PCR kit from Clontech (Palo Alto, CA, USA). Oligonucleotide primers for PCR were synthesized by Invitrogen (Carlsbad, CA, USA), based on sequence information from online sources $[15,16]$. In addition to standard, PCR-scorable, microsatellite markers [17], we also assayed 4 markers based on single-nucleotide polymorphisms that have been reported to differ between the $\mathrm{A} / \mathrm{J}$ and $\mathrm{C} 3 \mathrm{H} / \mathrm{HeJ}$ strains $[15,16]$. These markers, designated herein as SNP1-4, are described in detail in Additional file 2 and Additional file 3. To distinguish between $I l 2 \mathrm{ra}^{t m 1 D w}$ carriers and wild type mice, we used the 4-primer PCR assay recommended by the mouse supplier (The Jackson Laboratory). Two of these primers (5'CTGTGTCTGTAT GACCCACC 3', and 5' CAGGAGTTTCCTAAGCAACG $\left.3^{\prime}\right)$ correspond to Exon 2 of Il2ra, which in the mutant has been replaced with a PGK-neo cassette, and yield a 
280 bp amplimer with wild type DNA templates. The other two primers (5' CTTGGGTGGAGAGGCTATTC 3', and 5'AGGTGAGATGACAGGAGATC 3') correspond to the neo gene, and direct the amplification of a 280 bp amplimer from mutant DNA templates. To distinguish between Gata3 ${ }^{\operatorname{tm} 1 G s v}$ carriers and wild type mice, we used a 3-primer PCR assay of our own design. For this test, one primer-pair (forward primer, 5' CCCTAAACC CTCCTTTTTGC 3', and reverse primer 5' GATACCTC TGCACCGTAGCC 3') flanked the site of the engineered disruption in Exon 2, and produced a 399 bp amplimer with wild type templates; that forward primer and second reverse primer (5' GTTTTCCCAGTCACGACGTT 3'), based on sequences within in lacZ, yielded a 320 bp amplimer that is specific to the Gata $3^{\text {tmiGsv }}$ allele.

PCR products plus 2 ul loading buffer (bromophenol blue in 20\% Tris-buffered sucrose) were electrophoresed through 3.25\% NuSeive 3:1 agarose gels (Lonza, Rockland, ME, USA). Gels were stained with ethidium bromide $(0.5 \mathrm{ug} / \mathrm{mL})$ and photographed under ultraviolet light. For sequence analysis, about $1.5 \mathrm{ug}$ of individual PCR amplimers were concentrated into a 30 ul volume using QIAquick PCR Purification kits (Qiagen, Valencia, CA, USA). Purified amplimers were shipped to SeqWright, Inc. (Houston, TX, USA) for primer-extension analysis.

\section{mRNA analysis}

Total RNA was isolated from skin and thymus samples taken from 1-month-old mutant and wild type mice mice using the Nucleospin ${ }^{\circledR}$ RNA L kit by MachereyNagel (Easton, PA, USA). cDNA was generated using the SMARTer ${ }^{\text {TM }}$ RACE cDNA amplification kit (Clontech Laboratories). To amplify Gata3-specific cDNA, primer pairs that flanked exon junction boundaries were used in "step-down" PCR reactions. The products of this initial reaction were diluted $1: 10$ in Tricine- $\mathrm{KOH}$ buffer (10 mM, pH 8.5) plus $1 \mathrm{mM}$ EDTA, and were amplified again in standard PCR reactions using the same or nested primer pairs. Second-round amplimers were purified (as described above) and shipped to SeqWright, Inc., for primer-extension sequencing.

\section{Results}

\section{Mapping jal to a mouse chromosome}

To determine if jal might be carried on the mouse $\mathrm{X}$ chromosome, we conducted reciprocal crosses of homozygous mutant mice with wild type mice from the C57BL/6 J strain. Since the $F_{1}$ progeny of both genders were phenotypically wild type [see Additional file 4], we confirm that the jal mutation is recessive, and conclude that it must reside in an autosomal portion of the genome.

To determine an autosomal location for the jal mutation, we crossed $(\mathrm{C} 57 \mathrm{BL} / 6 \mathrm{~J} \times \mathrm{C} 3 \mathrm{H} / \mathrm{HeJ}-\mathrm{jal}) \mathrm{F}_{1} \mathrm{jal} /+$ females back to their jal/jal sire. This cross produced 43 mutants and 60 wild type progeny, not significantly different from the 1 mutant : 1 wild type ratio expected for a testcross $\left(\chi^{2}=2.81 ; P>0.09\right)$. DNA samples isolated from these 103 backcross $\left(\mathrm{N}_{2}\right)$ progeny were analyzed for 93 PCR-scorable microsatellite markers from throughout the mouse genome, including two from the pseudoautosomal region on the $\mathrm{X}$ and $\mathrm{Y}$ chromosomes. The average spacing of these markers was $16 \mathrm{cM}$, with the largest gap being a $31 \mathrm{cM}$ interval on Chr 4. Among the markers tested, only those from the centromeric portion of Chr 2 showed an inheritance pattern significantly different from the 1 parental : 1 recombinant ratio predicted if the marker and jal were independently assorted (see Figure 2). The largest deviation (82 parental and 21 recombinant types; $\chi^{2}=36.13$; $P<1.85 \times 10^{-9}$ ) was observed for marker D2Mit1, which is located $2.23 \mathrm{cM}$ from the centromeric end of Chr 2 [15].

\section{Meiotic fine-mapping}

To more precisely locate $j a l$ on proximal Chr 2 , we bred $(\mathrm{A} / \mathrm{J} \times \mathrm{C} 3 \mathrm{H} / \mathrm{HeJ}-j a l / \mathrm{J}) \mathrm{F}_{1}, j a l /+$ females back to $\mathrm{C} 3 \mathrm{H} /$ $\mathrm{HeJ-jal/jal} \mathrm{males,} \mathrm{since} \mathrm{this} \mathrm{strain} \mathrm{combination} \mathrm{offered}$ more microsatellite and single nucleotide polymorphisms (SNPs) than the $\mathrm{C} 57 \mathrm{BL} / 6 \mathrm{~J}$ and $\mathrm{C} 3 \mathrm{H} / \mathrm{HeJ}$ strain combination. These $\mathrm{N}_{2}$ mice were typed for jal and six microsatellite markers on proximal $\mathrm{Chr} 2$, as summarized in Figure 3. The 374 progeny from this backcross generation fit well with the expected 1 wild type : $1 \mathrm{mu}$ tant ratio expected for a testcross $\left(\chi^{2}=0.17 ; P>0.67\right)$, so mutants appear to be equally viable as their wild type, heterozygous littermates. Segregation of markers among this large $\mathrm{N}_{2}$ family indicates that jal is located between D2Mit359 and D2Mit80, a span of about $11 \mathrm{cM}$ that contains some $11.66 \mathrm{Mb}$ of DNA [16].

\section{Complementation testing between jal and a targeted mutation in I/2ra}

A recent genome-wide association study for alopecia areata (AA, OMIM \#104000) in humans has implicated several genes, including $I L-2 R A$ (for interleukin 2 receptor, alpha chain) in the development of disfiguring hair loss [18]. Because AA appears similar in at least some ways to the mutant jal/jal phenotype in mice [10], and because $I L-2 R A$ is located on human Chr $10 \mathrm{p} 15.1-$ a region that is orthologous with the D2Mit359 and D2Mit80 interval on Chr 2 in mouse-we decided to test jal for complementation with the recessive $I l 2 \mathrm{ra}^{t m 1 D w}$ loss-of-function mouse mutation [12]. Because mice homozygous for the targeted mutation show poor survival, we crossed $I l 2 \mathrm{ra}^{t m i D w} /+$ heterozygous females with jal/jal males. If jal were a defect in Il2ra, then the mice that inherit jal and Il2ra ${ }^{\text {tm1Dw }}$ could express no wildtype gene product, and would therefore be expected to show some mutant phenotype, perhaps as mild as 


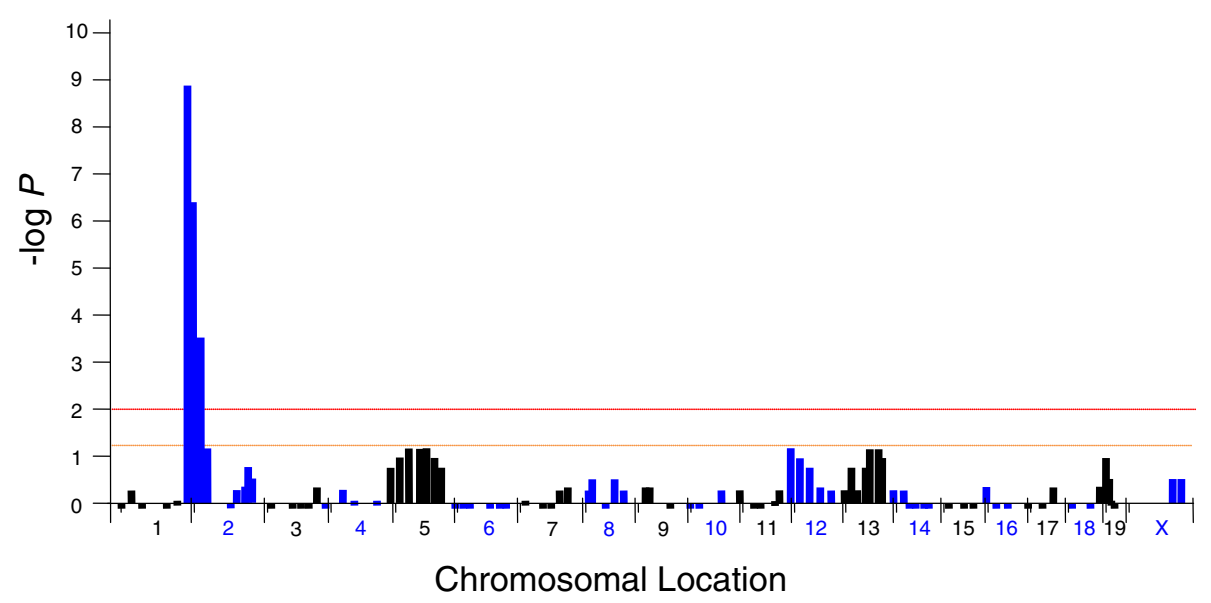

Figure 2 Inheritance of $\mathrm{jal}$ and 93 microsatellite markers, tested for goodness-of-fit with an independent-assortment model. Each microsatellite marker tested is represented by a single bar positioned on the horizontal axis to show its approximate location in the mouse genome. Markers from odd chromosomes are in black, those from even chromosomes are in blue. Results are plotted as negative logtransformed $P$ values calculated by the chi-squared method (with 1 degree of freedom). Bars descend below the baseline for those markers where more recombinant types (i.e., jal inherited from the $F_{1}$ mother together with a C57BL/6-derived marker allele, or jal ${ }^{+}$inherited with a $\mathrm{C} 3 \mathrm{H} / \mathrm{HeJ}$-derived marker) than parental types (jal inherited from the $\mathrm{F}_{1}$ mother together with a $\mathrm{C} 3 \mathrm{H} / \mathrm{HeJ}$-derived marker allele, or jal ${ }^{+}$inherited with a C57BL/6-derived marker) were observed in a set of 44 family members initially typed. Additional mice (up to all 103 in the backcross panel) were typed for markers that showed a surplus of parental types such that goodness-of-fit testing with the expected 1:1 ratio gave $P<0.1$. Only markers from proximal Chr 2 showed a significant (above the orange line, where $P<0.05$ ) or highly significant (above the red line, where $P<0.01)$ excess of parental types, indicative of linkage with jal.

defective vibrissae (as displayed by all jal/jal mutants) or perhaps as severe as the slower growth and progressive wasting (cachexia) seen in mice homozygous for $I l 2 r a^{t m I D w}[19]$. Alternatively, if $j a l$ and $I l 2 r a$ are distinct genes, then all of the progeny would be phenotypically normal (since both mutations are recessive).
This cross yielded 19 offspring that were typed by PCR for the $I l 2 \mathrm{ra}^{t m 1 D w}$ targeted disruption [Additional file 5] and observed for 30 weeks. DNA typing identified 11 $I l 2 \mathrm{ra}^{\text {tm } 1 \mathrm{Dw}}$ carriers (5 females and 6 males) and 8 mice without the targeted disruption (7 females and 1 male), not significantly different from the 1:1 ratio expected for

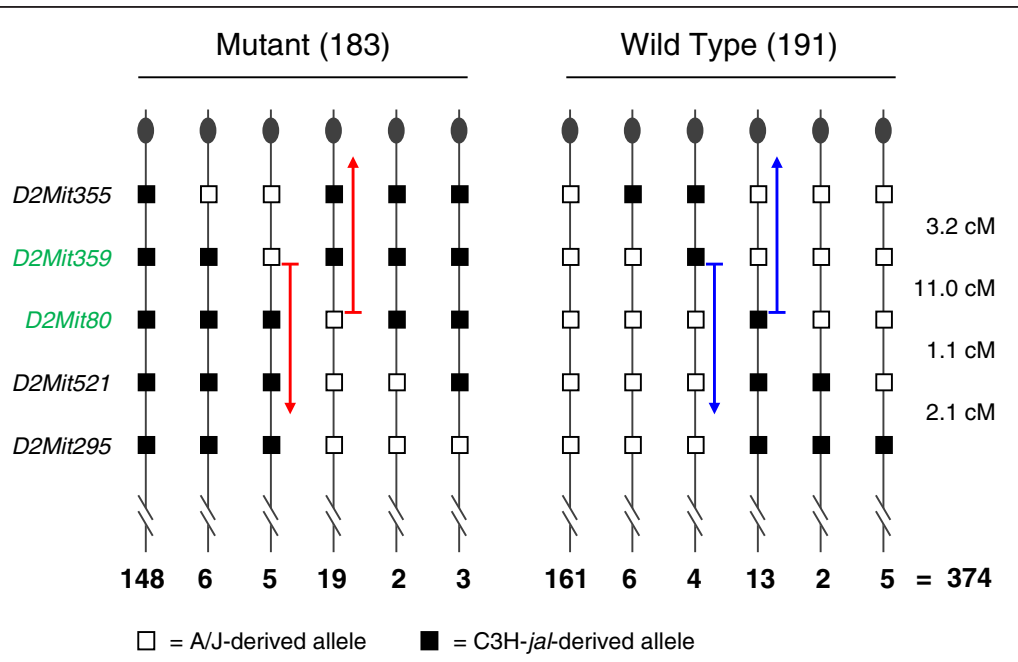

Figure 3 Segregation of jal and five microsatellite markers on proximal Chr $\mathbf{2}$ among $\mathbf{3 7 4}$ backcross mice. The five markers typed are shown to the left of the diagram. The haplotype transmitted by the heterozygous $F_{1}$ dam is depicted. Open boxes indicate A/J-derived alleles; solid boxes indicate $\mathrm{C} 3 \mathrm{H} / \mathrm{HeJ}$-derived alleles. The centromere is indicated by a knob at the top of each haplotype. The number of progeny inheriting each haplotype is shown below it. Genetic distances are shown to the right. The red arrows indicate that in these recombinant mutants, the mutant jal allele must be located below D2Mit359, but above D2Mit80. The blue arrows similarly indicate that in these recombinant wild type mice, the normal jal ${ }^{+}$allele must be located below D2Mit359, but above D2Mit80. 
a test $\operatorname{cross}\left(\chi^{2}=0.47 ; P=0.49\right)$. All of these mice (Il2ra ${ }^{t m 1 D w}$ carriers and noncarriers) displayed normal vibrissae and body hair. Furthermore, Il2ra ${ }^{t m 1 D w}$ carriers and noncarriers showed indistinguishable growth rates (over a period of 30 weeks), with no signs of the cachexia seen in $I l 2 \mathrm{ra}^{\text {tm1Dw}} / I l 2 \mathrm{ra}^{\text {tm1Dw }}$ controls [Additional file 6]. These data suggest that jal is not an allele of Il2ra.

\section{Refinement of the meiotic map for jal}

The 41 mice from the $(\mathrm{A} / \mathrm{J} \times \mathrm{C} 3 \mathrm{H} / \mathrm{HeJ}-j a l / \mathrm{J}) \mathrm{F}_{1} \times \mathrm{C} 3 \mathrm{H} /$ HeJ-jal/J backcross that were recombinant in the D2Mit359 and D2Mit80 interval were next typed for four, single-nucleotide polymorphisms designated $S N P 1$, SNP2, SNP3 and SNP4 (see Additional file 2 and Additional file 3). This analysis identified six crossovers between SNP1 and jal, and one crossover between jal and $S N P 2$, placing the jal mutation between these two markers (see Figure 4a), a $0.55 \mathrm{Mb}$ span that does not include Il2ra. Of the ten genes or predicted genes [16] that do map to this interval, only one-Gata3 (for GATA binding protein 3)-is known to be expressed in skin $[20,21]$.

\section{Evaluation of Gata3 as the possible genetic basis of the jal mutation}

To determine if jal could be a mutant allele of the Gata3 gene, we imported a mouse carrying an engineered Gata3 null allele, Gata3 ${ }^{\text {tm1Gsv }}[14]$, for complementation testing. To create litters of half experimental (doubly heterozygous) and half control offspring (carriers of the jal allele, only), we crossed Gata $3^{\text {tm1Gsv }} /+$ heterozygous females with jal/jal males. If jal is the result of a defect in Gata3, then the mice that inherit both jal and Gata3 $^{\text {tm1Gsv }}$ could express no wild-type gene product, and would therefore be expected to show defective coats and vibrissae. Alternatively, if jal and Gata3 are distinct genes, then the dihybrid progeny $\left(j a l /+\right.$, Gata $\left.^{\text {tm } 1 G s v} /+\right)$ would be phenotypically normal.

This cross yielded 22 offspring that were typed by PCR for the Gata3 ${ }^{\text {tm1Gsv }}$ targeted disruption. DNA typing identified 11 Gata $^{\text {tm1Gsv }}$ carriers (6 females and 5 males) and 11 mice without the disruption (10 females, 1 male), as expected for a test cross (Figure 5a). All Gata $3^{\text {tm } 1 \text { Gsv }}$ carriers displayed defective vibrissae and body hair (see Figure $5 \mathrm{c}$ and e), while those without the targeted mutation in Gata3 appeared phenotypically normal (Figure 5b
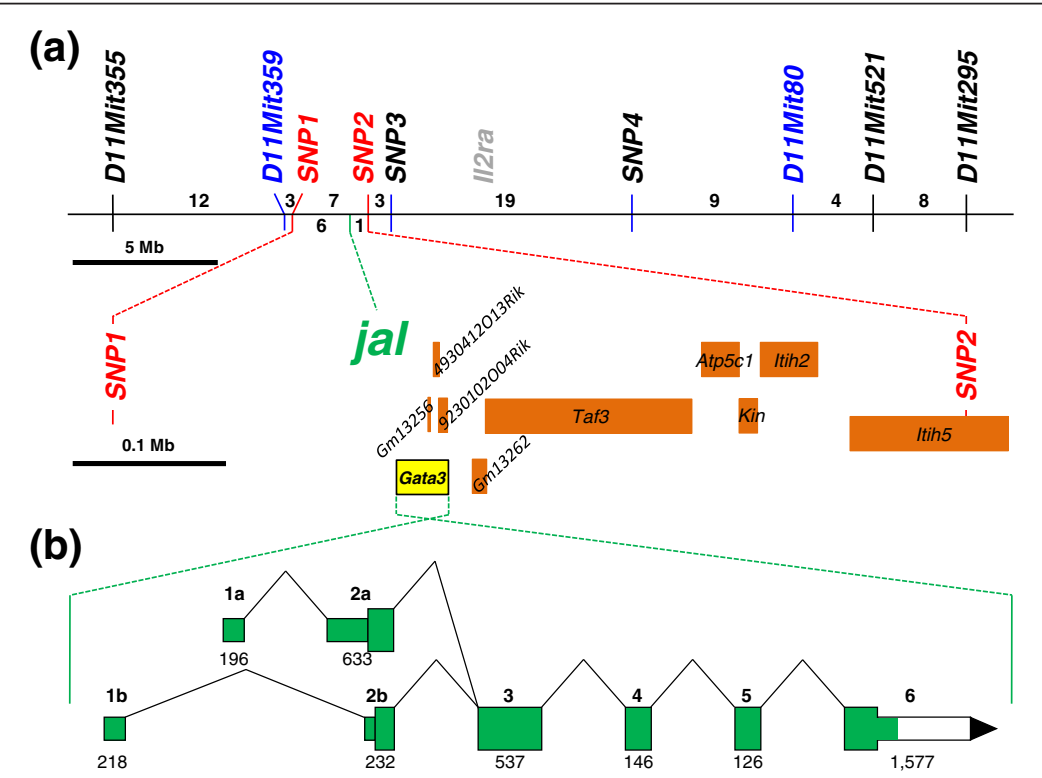

Figure 4 Physical maps of the jal region on mouse Chr 2. (a) Molecular markers and genes on mouse Chr 2 that are linked with jal. Segregation data from the 374-member backcross panel shown in Figure 3 placed jal between microsatellite markers D2Mit359 and D2Mit80 (shown in blue), an interval that also includes I/2ra (shown in gray). Single-nucleotide polymorphisms (SNP1-4, see Additional file 2 and Additional file 3) were used to more precisely locate crossovers among the 41 mice recombinant in this interval. The number of crossovers located between the various pairs of adjacent markers are shown on the chromosome map, which is drawn to the $5 \mathrm{Mb}$ scale shown. Seven recombinants located jal between SNP1 and SNP2 (shown in red). The region between SNP1 and SNP2 is expanded below the chromosome map (drawn to the 0.1 MB scale bar shown), to show the locations of the 10 candidate genes (represented by orange boxes) that populate this span. Of these ten genes, only one, Gata3 (shown in yellow), is known to be expressed in skin. (b) The Gata3 gene is expanded to show the arrangement of exons, where taller boxes are coding regions and shorter boxes are the $5^{\prime}$ or $3^{\prime}$ untranslated regions. Gata3 is transcribed from the reverse strand, but is drawn here so that the six exons are shown in ascending numerical order. The length of each exon (in bp) is shown below the corresponding box. The portions of exons shaded green have been sequenced in $\mathrm{C} 3 \mathrm{H} / \mathrm{HeJ}$ and $\mathrm{C} 3 \mathrm{H} / \mathrm{HeJ}$-jal/J DNA, but no differences were found. 
and d). Thus, jal and Gata3 ${ }^{\text {tm1Gsv }}$ fail to complement, suggesting that these mutations are allelic.

All coding regions of the Gata3 gene, plus the 5' untranslated regions encoded by two alternative 1st exons (see Figure $4 \mathrm{~b}$ for transcript diagram and summary) were sequenced in DNA isolated from $\mathrm{C} 3 \mathrm{H} / \mathrm{HeJ}$ and $\mathrm{C} 3 \mathrm{H} / \mathrm{HeJ}-$ $\mathrm{jal} / \mathrm{J}$ mice. However, we found no differences in DNA sequence between these coisogenic wild type and mutant strains. In addition, using total RNA isolated from skin and from thymus, we amplified (and sequenced) only identically-spliced Gata3 cDNA from both wild type C3H/ $\mathrm{HeJ}$ and $\mathrm{C} 3 \mathrm{H} / \mathrm{HeJ}-j a l / J$ mutant mice (see Additional file 7).

\section{Discussion}

The results presented suggest to us that the jal mutation is a mutant allele of the Gata3 gene on mouse Chr 2.
We therefore recommend that the jal designation be changed to Gataj ${ }^{j a l}$. While we have not yet been able to pinpoint a sequence-level change in Gata3 ${ }^{\text {jal }}$, our analysis has mostly been limited to coding regions. We hypothesize that the Gata3 $3^{j a l}$ defect is likely to be a regulatory mutation (perhaps located in the promoters, introns, or $3^{\prime}$ untranslated region) that-in some fashion-impacts expression, processing, or degradation of the Gata3 ${ }^{j a l}$ transcript, although we find that the Gata3-001 transcript appears to be normally spliced. (We found no evidence for expression of the alternative Gata3-201 transcript in total RNA isolated from skin or thymus.) Quantitative and qualitative evaluation of Gata3 transcripts or protein in the epidermis and hair follicles of $\mathrm{C} 3 \mathrm{H} / \mathrm{HeJ}-j a l$ mice versus wild type controls could help refine this array of possibilities.
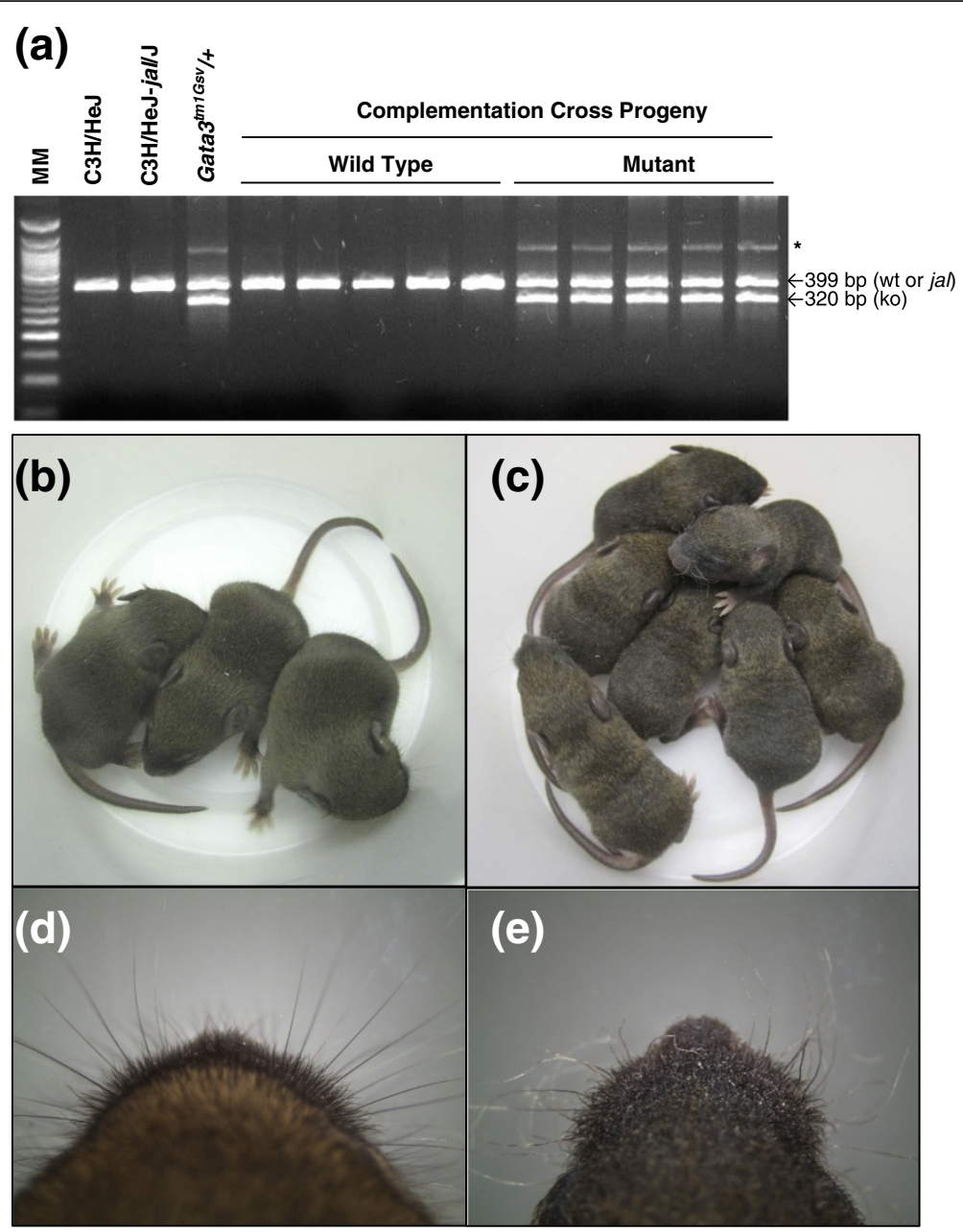

Figure 5 The recessive jal and Gata ${ }^{\text {tm1Gsv }}$ mutations fail to complement in doubly heterozygous mice. (a) Typical results of a 3-primer PCR test designed to identify Gata ${ }^{\text {tm }}$ Gsv carriers. The 320 bp band and a fainter, high-molecular-weight band (marked with an asterisk) are specific to the mutant allele. The size standard shown (MM) is a 50 base pair ladder. A 10-day-old litter from a cross of Gata $3^{\text {tm } / G s v} / \mathrm{Gata}^{+} \times$jalljal included pups displaying wild type (b) or mutant (c) hair development. All phenotypically wild type pups showed the 399 bp band only, and the phenotypically mutant pups all carried the targeted mutation. The snouts of one wild type (d) and one mutant (e) pup from the same litter are enlarged to show normal vs. defective vibrissae formation, respectively. 
This prediction (that the Gataj ${ }^{\text {jal }}$ defect is likely to be a regulatory mutation) does seem consistent with the variable phenotypic presentation of focal alopecia that we observe in Gata3 $^{j a l} /$ Gata3 $^{\text {jal }}$ mice (see Additional file 1). Since at least some patches of normal fur are seen on most if not all mutants (with some mutants showing almost entirely normal coats), we anticipate that a standard primary protein sequence (albeit improperly regulated) is likely to be encoded by the Gata3 $3^{j a l}$ allele.

The positional assignment of jal did not reveal (as with our introductory examples, refs. 1-9) an unsuspected function of Gata3 in skin, since the study of mouse strains engineered to carry targeted mutations have previously indicated a role for Gata3 in hair follicle development and skin cell lineage determination. Mice homozygous for germline Gata3 null mutations die around embryonic day 11 [22,23], precluding a detailed assessment of the functional role of Gata3 in hair follicle morphogenesis. However, some investigators have rescued mutant skin by transplantation to athymic hosts [24], or else ablated Gata3 specifically in the epidermis and hair follicles to reveal a crucial role in skin [25]. Since the mouse juvenile alopecia phenotype (patchy hair loss) is distinct from that of these conditionallytargeted mutants (complete baldness) - whatever its molecular basis-we believe that Gataj ${ }^{j a l}$ likely offers a novel mutant allele, compared to the existing set of engineered Gata3 disruptions. Addition of this viable and phenotypically-unique natural variant to the Gata3 mutational inventory will surely allow new approaches to the functional analysis of this locus, just as the recent assignment of the spontaneous mouse frizzy ( fr) and rat "hairless" $\left(f_{r}{ }^{C R}\right)$ mutations to the prostasin gene [26] has productively advanced the in vivo analysis of Prss 8 function in mammalian skin [27-29].

Haploinsufficiency of human GATA3 (due to loss-offunction mutation of GATA3) causes a dominantlyinherited syndrome of hypoparathyroidism, sensorineural deafness, and renal disease (HDR, OMIM \#146255) also known as Barakat syndrome. Notably, HDR syndrome does not appear to involve immune-related disorders or alopecia $[30,31]$. The mouse Gata $3^{\text {tm1Gsv }}$ mutation has been shown to generate deafness in heterozygotes [32-34], and is considered a model for HDR. It would certainly be interesting to investigate parathyroid, cochlear, and renal function in Gata3 $^{j a l}$ homozygotes and heterozygotes. In any case, a molecular explanation for the distinct modes of inheritance and phenotypic presentations of juvenile alopecia in mice versus HDR in humans will require discovery of the precise structure of the Gata3 ${ }^{\text {jal }}$ allele.

Histological observation of immune cell infiltrates associated with follicular dystrophy in AA [35,36] combined with Petukhova et al.'s linkage of genes involved in both innate and acquired immunity (including $I L$ -
$2 R A$ ) to AA susceptibility [18] seem to firmly establish AA as an autoimmune disorder. Although Gata3 is known to play a crucial role in $\mathrm{T}$ cell development $[22,37]$, our elimination of Il2ra as the basis of the mutant phenotype as well as McElwee et al.'s failure to detect any signs of hair follicle inflammation in jal/jal mutants [10] suggest that mouse juvenile alopecia does not provide an ideal model for AA. However, it remains possible that juvenile alopecia could provide an animal model for at least some forms of focal alopecia which may have their primary defect in the hair follicle and lack an inflammatory component, but which may nonetheless be diagnosed as AA based on similar pathophysiology (i.e., patchy hair loss). Indeed, the future study of mouse juvenile alopecia may be helpful in identifying such a homologous human condition, defining approaches for distinguishing that disorder from AA, and in developing appropriate, specialized treatments.

\section{Conclusions}

The recessive jal mutation in mice maps to proximal Chr 2, and has been shown by complementation testing to be a variant allele of the Gata3 gene. While further study will be needed to discover the molecular defect in Gata3 that is the basis of the mutant phenotype, this spontaneous mouse variant promises to provide an animal model for some forms of focal alopecia in humans that have their primary defect in the hair follicle and lack an inflammatory component.

\section{Additional files}

Additional file 1: Three-month-old mutants from a (C3H/HeJ-jal/J $\mathrm{x}$ $\mathrm{C} 57 \mathrm{BL} / 6 \mathrm{~J}) \mathrm{F}_{1} \times \mathrm{C} 3 \mathrm{H} / \mathrm{HeJ}$-jal/J backcross display variable expressivity of the juvenile alopecia phenotype.

Additional file 2: Description of SNP markers referred to in the Ramirez et al. (2013) text.

Additional file 3: Location of SNP markers referred to in the Ramirez et al. (2013) text.

Additional file 4: $F_{1}$ data from reciprocal crosses in mice tests the juvenile alopecia mutation (jal) for $\mathrm{X}$ versus autosomal linkage.

Additional file 5: DNA typing for the $112 \mathrm{ra}^{\text {tm } 1 \mathrm{Dw}}$ or $112 \mathrm{ra}^{+}$alleles among the progeny of a complementation cross, $\| 12 \mathrm{ra}^{t m 1 D w} / 112 \mathrm{ra}^{+} \mathrm{x}$ jal/jal.

Additional file 6: The recessive jal and $112 \mathrm{ra}^{\text {tm1Dw }}$ mutations complement in doubly heterozygous mice.

Additional file 7: Sequence analysis of Gata3 splice junctions in wild-type $\mathrm{C} 3 \mathrm{H} / \mathrm{HeJ}$ and mutant $\mathrm{C} 3 \mathrm{H} / \mathrm{HeJ}-\mathrm{jal}$ cDNA.

Competing interests

The authors declare that they have no competing interests.

\section{Authors' contributions}

FR led all aspects of the genome-wide linkage screen, including experimental design, data acquisition and interpretation. AMF led all aspects of the Chr 2 fine-mapping, Gata3 complementation testing, and sequencing of Gata3; including experimental design, data acquisition and interpretation. KMC, LAR and AMF conducted the Gata3 cDNA analysis. NV-S conducted 
complementation testing between jal and II2ra. EBA, AS, JMH and DVS made substantial contributions to the genome-wide and regional genetic analyses. LAR, KMC and SRH contributed significantly to the SNP marker analysis. TRK conceived of the study, carried out all procedures involving mice, and drafted the manuscript. All authors read, edited, and approved the final manuscript.

\section{Authors' information}

TRK is a professor in the Department of Biomolecular Sciences at Central Connecticut State University (New Britain, CT). FR was a student in the Master of Arts program in Biomolecular Sciences, and AMF, EBA, AS, NV-S, JMH, LAR, KMC, SRH and DVS were undergraduates majoring in Biomolecular Sciences or Biochemistry at CCSU when they conducted this research.

\section{Acknowledgements}

The authors thank CCSU undergraduates Randy Taylor, Adrian Pacheko, Anthony Ferrante, Nisrine Dagamseh, Amarilis Perez; and numerous highschool interns (including Edie Tinker, Mariam Hasan, Somaly Chhean, Rick Deschenes, Alicia Davis, Joshua Wrice, Marcelino Thillet, Ananda Thillet, Danerick Peralta, Diego Peralta, Ashley Feliciano, Krystal Garcia, Kayla Garcia, Jodalis Montalvo, Milagros Molina, Brianna Cirinna, and Rebecca Fuentes) for help with marker typing. We also thank Dr. James Douglas Engel (Department of Cell and Developmental Biology, University of Michigan, Ann Arbor, MI, USA) for donation of mice carrying the Gata ${ }^{\text {tmiGsv }}$ null mutation, and Mary Mantzaris for excellent animal care. This work was supported by AREA grant 1R15AR059572 from the National Institute of Arthritis and Musculoskeletal and Skin Diseases (NIAMS).

Received: 12 October 2012 Accepted: 22 March 2013 Published: 9 May 2013

\section{References}

1. Schultz LD, Schweitzer PA, Rajan TV, Yi T, Ihle JN, Matthews RJ, Thomas ML, Beier DR: Mutations at the murine motheaten locus are within the hematopoietic cell protein-tyrosine phosphatase (Hcph) gene. Cell 1993, 73:1445-1454

2. Hébert JM, Rosenquist T, Götz J, Martin GR: FGF5 as a regulator of the hair growth cycle: evidence from targeted and spontaneous mutations. Cell 1994, 78:1017-1025.

3. Luetteke NC, Phillips HK, Qiu TH, Copeland NG, Earp HS, Jenkins NA, Lee DC: The mouse waved-2 phenotype results from a point mutation in the EGF receptor tyrosine kinase. Genes Dev 1994, 8:399-413.

4. Nehls M, Pfeifer D, Schorpp M, Hedrich H, Boehm T: New member of the winged-helix protein family disrupted in mouse and rat nude mutations. Nature 1994, 372:103-107.

5. Araki R, Fujimori A, Hamatani K, Mita K, Saito T, Mori M, Fukumura R, Morimyo M, Muto M, Itoh M, Tatsumi K, Abe M: Nonsense mutation at Tyr-4046 in the DNA-dependent protein kinase catalytic subunit of severe combined immune deficiency mice. Proc Natl Acad Sci USA 1997, 94:2438-2443.

6. Moulson CL, Martin DR, Lugus JJ, Schaffer JE, Lind AC, Miner JH: Cloning of wrinkle-free, a previously uncharacterized mouse mutation, reveals crucial roles for fatty acid transport protein 4 in skin and hair development. Proc Natl Acad Sci USA 2003, 9:5274-5279.

7. Mannan AU, Roussa E, Kraus C, Rickmann M, Maenner J, Nayernia K, Krieglstein K, Reis A, Engel W: Mutation in the gene encoding lysosomal acid phosphatase (Acp2) causes cerebellum and skin malformation in mouse. Neurogenetics 2004, 5:229-238.

8. Herron BJ, Rao C, Liu S, Laprade L, Richardson JA, Olivieri E, Semsarian C, Millar SE, Stubbs L, Beier DR: A mutation in NFkB interacting protein 1 results in cardiomyopathy and abnormal skin development in wa3 mice. Hum Mol Genet 2005, 14:667-677.

9. Radden LA II, Child KM, Adkins EB, Spacek DV, Feliciano AM, King TR: The wooly mutation (wly) on mouse Chromosome 11 is associated with a genetic defect in Fam83g. BMC Res Notes 2013. doi:10.1186/1756-0500-6189. In Press.

10. McElwee KJ, Boggess D, King LE, Sundberg JP: Alopecia areata versus juvenile alopecia in $\mathrm{C} 3 \mathrm{H} / \mathrm{HeJ}$ mice: tools to dissect the role of inflammation in focal alopecia. Exp Dermatol 1999, 8:354-355.
11. Ramirez F: Making a chromosomal assignment for the juvenile alopecia (jal) mutation in mice. Central Connecticut State University, Department of Biomolecular Sciences; 2012. M.A. dissertation.

12. Willerford DM, Chen J, Ferry JA, Davidson L, Ma A, Alt FW: Interleukin-2 receptor a chain regulates the size and content of the peripheral lymphoid compartment. Immunity 1995, 3:521-530.

13. Kuo L-M, Rusk CM, Robb RJ: Structure-function relationships for the IL-2 receptor system II: localization of an IL-2 binding site on high and low affinity receptors. J Immunol 1986, 137:1544-1551.

14. van Doorninck JH, van der Wees J, Karis A, Goedknegt E, Engel JD, Coesmans M, Rutteman M, Grosveld F, De Zeeuw Cl: GATA-3 is involved in the development of serotonergic neurons in the caudal raphe nuclei. J Neurosci 1999, 19:1-8. RC12.

15. Mouse Genome Database (MGD). Mouse Genome Database Group: The Mouse Genome Informatics website. Bar Harbor, ME: The Jackson Laboratory. (Accessed October, 2012): Available at http://www.informatics.jax.org.

16. The European Bioinformatics Institute (EBI) and the Welcome Trust Sanger Institute (WTSI): Mouse Genome Sequencing Consortium. Release 65 (Accessed October, 2012): Available at http://www.ensembl.org/ Mus_musculus/.

17. Dietrich WF, Miller J, Steen R, Merchant MA, Damron-Boles D, Husain Z, Dredge R, Daly MJ, Ingalls KA, O'Connor TJ: A comprehensive genetic map of the mouse genome. Nature 1996, 380:149-152.

18. Petukhova L, Duvic M, Hordinsky M, Norris D, Price V, Shimomura Y, Kim H, Singh $\mathrm{P}$, Lee A, Chen WV, Meyer KC, Paus R, Jahoda CAB, Amos Cl, Gregersen PK, Christiano AM: Genome-wide association study in alopecia areata implicates both innate and adaptive immunity. Nature 2010, 466:113-118.

19. Poussier $P$, Ning $T$, Chen J, Banerjee $D$, Julius M: Intestinal inflammation observed in IL-2R/IL-2 mutant mice is associated with impaired intestinal lymphopoiesis. Gastroenterology 2000, 118:880-891.

20. Oosterwegel M, Timmerman J, Leiden J, Clevers H: Expression of GATA-3 during lymphocyte differentiation and mouse embryogenesis. Dev Immunol 1992, 3:1-11.

21. Lakshmanan G, Lieuw KH, Lim KC, Gu Y, Grosveld F, Engel JD, Karis A: Localization of distant urogenital system-, central nervous system-, and endocardium-specific transcriptional regulatory elements in the GATA-3 locus. Mol Cell Biol 1999, 19:1558-1568.

22. Pandolfi PP, Roth ME, Karis A, Leonard MW, Dzierzak E, Grosveld FG, Engel $J D$, Lindenbaum MH: Targeted disruption of the GATA3 gene causes severe abnormalities in the nervous system and in fetal liver haematopoiesis. Nat Genet 1995, 11:40-44.

23. Lim KC, Lakshmanan G, Crawford SE, Gu Y, Brosveld F, Engel JD: Gata3 loss leads to embryonic lethality due to noradrenaline deficiency of the sympathetic nervous system. Nat Genet 2000, 25:209-212.

24. Kaufman CK, Zhou P, Pasolli HA, Rendl M, Bolotin D, Lim K-C, Dai X, Alegre $M-L$, Fuchs E: GATA-3: an unexpected regulator of cell lineage determination in skin. Genes Dev 2003, 17:2108-2122.

25. Kurek D, Garinis GA, van Doorninck JH, van der Wees J, Grosveld FG: Transcriptome and phenotypic analysis reveals Gata3-dependent signaling pathways in murine hair follicles. Development 2007, 134:261-272.

26. Spacek DV, Perez AF, Ferranti KM, Wu LK-L, Moy DM, Magnan DR, King TR: The mouse frizzy $(f r)$ and rat 'hairless' $\left(f_{r}{ }^{C R}\right)$ mutations are natural variants of protease serine S1 family member 8 (Prss8). Exp Dermatol 2010, 19:527-532.

27. Frateschi S, Keppner A, Malsure S, Iwaszkiewicz J, Sergi C, Merillat A-M, Fowler-Jager N, Randrianarison N, Planès C, Hummler E: Mutations of the serine protease CAP1/Prss8 lead to reduced embryonic viability, skin defects and decreased ENaC activity. Am J Pathol 2012, 181:605-615.

28. Szabo R, Sales KU, Kosa P, Shylo NA, Godiksen S, Hansen KK, Friis S, Gutkind JS, Vogel LK, Hummler E, Camerer E, Bugge TH: Reduced prostasin (CAP1/PRSS8) activity eliminates $\mathrm{HAl}-1$ and $\mathrm{HAl}-2$ deficiency-associated developmental defects by preventing matriptase activation. PLoS Genet 2012, 8:e1002937.

29. Frateschi S, Camerer E, Crisante G, Rieser S, Membrez M, Charles R-P, Beermann F, Stehle J-C, Breiden B, Sandhoff K, Rotman S, Haftek M, Wilson A, Ryser S, Steinhoff M, Coughlin SR, Hummler E: PAR2 absence completely rescues inflammation and ichthyosis caused by altered CAP1/Prss 8 expression in mouse skin. Nature Commun 2011, 2:161.

30. Van Esch H, Groenen P, Nesbit MA, Schuffenhaurer S, Lichtner $P$, Vandrlinden G, Harding B, Beetz R, Bilous RW, Holdaway I, Shaw NJ, 
Fryns J-P, Van de Ven W, Thakker RV, Devriendt K: GATA3 haploinsufficiency causes human HDR syndrome. Nature 2000, 406:419-422.

31. Muroya $K$, Hasegawa T, Ito $Y$, Nagai T, Isotani H, Iwata Y, Yamamoto $K$, Fujimoto S, Seishu S, Fukushima Y, Hasegawa Y, Ogata T: GATA3 abnormalities and the phenotypic spectrum of HDR syndrome. $J$ Med Genet 2001, 38:374-380.

32. Karis A, Pata I, van Doorninck JH, Grosveld F, de Zeeuw Cl, de Caprona D, Fritzsch B: Transcription factor GATA-3 alters pathway selection of olivocochlear neurons and affects morphogenesis of the ear. J Comp Neurol 2001, 429:615-630.

33. van der Wees J, van Looij MA, de Ruiter MM, Elias $H$, van der Burg $H$, Liem SS, Kurek D, Engel JD, Karis A, van Zanten BG, de Zeeuw Cl, Grosveld FG, van Doorninck JH: Hearing loss following Gata3 haploinsufficiency is caused by cochlear disorder. Neurobiol Dis 2004, 16:169-178.

34. van Looij MA, van der Burg $H$, van der Giessen RS, de Ruiter MM, van der Wees J, van Doorninck JH, De Zeeuw Cl, van Zanten GA: GATA3 haploinsufficiency causes a rapid deterioration of distortion product otoacoustic emissions (DPOAEs) in mice. Neurobiol Dis 2005, 20:890-897.

35. Gilhar A, Paus R, Kalish RS: Lymphocytes, neuropeptides, and genes involved in alopecia areata. J Clin Invest 2007, 117:2019-2027.

36. Gilhar A, Shalaginov R, Assy B, Serafimovich S, Kalish RS: Alopecia areata is a T-lymphocyte mediated autoimmune disease: lesional human T-lymphocytes transfer alopecia areata to human skin grafts on SCID mice. J Investig Dermatol Symp Proc 1999, 4:207-210.

37. Ting CN, Olson MC, Barton KP, Leiden JM: Transcription factor GATA-3 is required for development of the T-cell lineage. Nature 1996, 384:474-478.

doi:10.1186/1471-2156-14-40

Cite this article as: Ramirez et al:: The juvenile alopecia mutation (jal) maps to mouse Chromosome 2, and is an allele of GATA binding protein 3 (Gata3). BMC Genetics 2013 14:40.

\section{Submit your next manuscript to BioMed Central and take full advantage of:}

- Convenient online submission

- Thorough peer review

- No space constraints or color figure charges

- Immediate publication on acceptance

- Inclusion in PubMed, CAS, Scopus and Google Scholar

- Research which is freely available for redistribution 